\title{
Métodos digitales para el estudio de la fotografía compartida. Una aproximación distante a tres ciudades iberoamericanas en Instagram.
}

\author{
Digital Methods for the Study of Shared Photography. A \\ Distant Approach to three Iberoamerican Cities on Instagram
}

\author{
Gabriela Sued \\ Instituto Tecnológico de Monterrey \\ Escuela de Humanidades y Educación \\ gabriela.sued@gmail.com (MÉXICO)
}

Recibido: 10.092017

Aceptado: 24.04.2018

\section{RESUMEN}

En este trabajo abordamos el estudio empírico de la fotografía urbana compartida en Instagram. Estudiamos los casos de tres ciudades iberoamericanas etiquetadas como: \#buenosaires, \#cdmx y \#madrid. Proponemos una aproximación distante (Moretti, 2007, 2015) a partir de cuatro técnicas de analítica de datos (Gandolmi y Haider, 2015) aplicadas a la investigación cultural. Indagamos acerca de los modos en que las ciudades son representadas por los usuarios en la plataforma, los usos sociales de los hahstags, y a nivel metodológico, las posibilidades de la analítica de datos para realizar un estudio sociocultural. En base al diseño metodológico y el análisis empírico establecemos conclusiones sobre los métodos de investigación basados en datos, sobre las representaciones urbanas, y sobre el uso y las prácticas de los usuarios en Instagram.

\section{PALABRAS CLAVE}

Cultura digital, métodos digitales, fotografía compartida, medios sociales.

\begin{abstract}
In this article we address the empirical study of shared urban photography in Instagram. We study how three Iberoamerican cities, Buenos Aires, México y
\end{abstract}


Madrid, are represented in the social plaftorm through a dataset of five thousands pictures labeled with the hashtags \#buenosaires, \#cdmx and \#madrid respectively. We propose a distant approach (Moretti, 2007, 2015) based on four techniques of data analysis (Gandolmi and Haider, 2015) applied to cultural research. We inquire about the ways in which the cities are represented by the users on the platform, identifying also some social uses of hahstags. At the methodological level, we explore the possibilities of data analytics to conduct a sociocultural study. At last, we draw some conclusions about data-based research methods, the highlights of urban representations for each city in a comparative way, and the social usage of shared photography in Instagram.

\section{KEY WORDS}

Digital culture, digital methods, shared photography, social media.

\section{INTRODUCCIÓN}

Debido a la generalización del uso de cámaras fotográficas en teléfonos móviles y a la posibilidad de su inmediata publicación en redes sociales, la fotografía compartida ha devenido una parte fundamental de la comunicación on-line. Sin embargo, ha sido menos estudiada que los objetos textuales publicados en algunas plataformas sociales, por ejemplo en Twitter. (Highfield y Leaver, 2016). Recientemente la investigación académica comienza a analizar el contenido visual generado por los usuarios. Estas temáticas y nuevos modos de producción de información son crecientemente abordados en análisis científicos y críticos con metodologías innovadoras, como la analítica cultural (Manovich, 2009) los métodos digitales (Rogers, 2009) y la visualización de información (Niederer y Taudin Chabot, 2015).

Algunos autores entienden que el estudio de objetos digitales, sean éstos textuales o visuales, pueden profundizar no sólo en el mayor entendimiento de los nuevos medios y prácticas digitales. También pueden proveer conocimientos sobre ciertos aspectos de la vida social a partir del análisis de los patrones trazados por el uso generalizado de las infraestructuras digitales. (Savage and Burrows, 2007, Rogers, 2013 y Marres, 2017). Si bien en la literatura anglosajona existe un corpus de literatura que aborda el estudio social basado en datos tanto en términos metodológicos como empíricos, la investigación con métodos digitales apenas emerge en las publicaciones de lengua española (Meneses Rocha, 2018). Se hace necesaria entonces una evaluación de los métodos digitales a fin de identificar sus posibilidades, alcances y limitaciones en el contexto iberoamericano.

Siguiendo esas líneas de investigación, abordamos un aspecto importante de la cultura digital actual: la fotografía urbana compartida en la plataforma Instagram. En la última década las ciudades toman un rol protagónico en los trabajos propios de la analítica cultural (Hochman y Manovich, 2013, Förster, Lammerz 
y otros, 2014), en proyectos digitales visuales (Presner, Shepard y otros, 2010), en el estudio de las dinámicas y las estructuras urbanas (Colombo, Ciuccarelli y Mauri, 2017), y en los modos personales de retrato, como las selfies y fotografías de perfil (Manovich, Stefaner y Yazdani, 2014). Sin embargo, no ha sido estudiado el modo en que las ciudades de Iberoamérica son representadas en las redes sociales de fotografía compartida desde la perspectiva del análisis basado en datos.

El propósito de este trabajo es doble: por un lado sistematizar una metodología para el abordaje de la fotografía compartida basado en el análisis cultural de datos con métodos digitales (Rogers, 2009) y por el otro realizar el estudio de un corpus de fotografías compartidas en la red social Instagram de temática urbana, con el propósito de extender la comprensión sobre la práctica fotográfica e identificar los modos en que los usuarios de la plataforma observan, experimentan y representan las ciudades.

De acuerdo con el pensamiento culturalista de Hall (2013), representar es dar significado a la experiencia otorgándole valor e identidad. Los significados organizan y regulan las prácticas sociales, ya que éstas incluyen la construcción de identidades, representaciones y formas de socialización humana, y forman parte de la cultura entendida como sistema semiótico (Geertz, 1973). En este trabajo los métodos digitales permiten recolectar y analizar el corpus, pero el abordaje teórico interpretativo se realiza desde los estudios culturales y la sociosemiótica. (Verón, 1987 y 2012). Estas aproximaciones consideran la ciudad como una construcción cultural dinámica que incluye las prácticas y representaciones de sus habitantes (de Certeau, 1996). En el contexto de la globalización las ciudades son atravesadas por las comunicaciones digitales en red.Dejan ser un territorio geográficamente localizado para transformarse en redes que conectan espacios, flujos de información, formas de economía, y modos de representación (Sassen, 1995). La experiencia actual de las ciudades se encuentra atravesada por tecnologías digitales de movilidad, localización y representación y se construye colectivamente. Las ciudades globales poseen un componente simbólico y cultural que incluye a la fotografía compartida. La cultura visual es parte de la vida social (Rose, 2016): estudiar la fotografía urbana compartida puede permitirnos saber más sobre la vida social en las ciudades actuales.

Asumimos que las etiquetas con nombres de ciudades relacionan fotografías que de formas diferentes expresan representaciones y experiencias urbanas construidas colectivamente. Profundizamos en las formas en que las ciudades son representadas desde el punto de vista de los usuarios de la plataforma, describimos sus especificidades, e identificamos el uso social de las etiquetas donde se publican miles de fotos diariamente. Planteamos las siguientes preguntas de investigación: ¿Qué clase de patrones de representación estéticos y temáticos se observan en cada una de las etiquetas? ¿Es la fotografía compartida en Instagram una práctica comunitaria o sólo puede verse como una colección dispersa de fotografías? ¿Qué usos sociales se da a los etiquetas urbanas, más allá de ser meros organizadores de fotografías sobre ciudades? ¿Qué tipo de experiencias ciudadanas o formas de vivir en la ciudad, se identifican en las fotografías es- 
tudiadas? ¿Pueden identificarse elementos estables en los aspectos temáticos, estéticos y comunitarios de la práctica que permita pensar en la formación de un género discursivo propio?

A tal fin de responder estas preguntas hemos recolectado un conjunto de fotografías etiquetadas como \#buenosaires, \#cdmx (México) y \#madrid, publicadas en Instagram durante la primera semana de octubre de 2016. Las ciudades elegidas pertenecen a los países que lideran el uso de Instagram de habla hispana. En primer lugar se encuentra Argentina, con 9,1 millones de usuarios activos, en segundo lugar España, con 8, 5 millones de usuarios, y en tercer lugar México, con 8,39 millones de usuarios (Statista, 2016). Consultas realizadas en octubre de 2016 al explorador de Instagram indicaban que la etiqueta \#buenosaires contaba con más de cuarenta y cinco millones de publicaciones, mientras que \#cdmx albergaba más de veintiocho millones de imágenes, y \#madrid registraba más de quince millones de fotografías. Al momento no ha sido estudiado el modo en que estas ciudades son abordadas en la fotografía compartida.

Definimos como etiqueta o hashtag la inscripción textual e intencional con la que los usuarios clasifican, agrupan y hacen visibles sus fotografías. Las etiquetas pueden ser navegadas por los usuarios a partir de la interfaz de Instagram. Como afirman Burgess y Bruns (2015) y Highfield y Leaver (2014), las etiquetas han permitido la formación de públicos ad-hoc y comunidades que se congregan en torno a un tema, sea de un modo efímero, como sucede en Twitter, o de un modo más estable, como parece suceder en Instagram, donde es común el etiquetado de fotografías. Suponemos que el etiquetado genera nuevos públicos y otorga visibilidad y sociabilidad a la fotografía compartida.

Este trabajo considera tanto la dimensión digital de esas interacciones como una interpretación crítica que pueda identificar el papel que los objetos digitales juegan en la producción de la cultura contemporánea. Emplea una metodología de investigación mixta que combina el análisis cuantitativo, el empleo de software de procesamiento de datos textuales y numéricos y la interpretación de resultados desde una perspectiva sociocultural.

\section{LA FOTOGRAFÍA COMPARTIDA EN INSTAGRAM}

A la vez que proliferan los contenidos creados por los usuarios en la última década, la fotografía experimenta sustanciales cambios. En la década del noventa Fontcuberta define a la fotografía como "un signo que, efectivamente, requiere para su consecución una relación de causalidad física con el objeto. El objeto se representa a sí mismo mediante la luz que refleja. La imagen no es más que el rastro del impacto de esa luz sobre la superficie fotosensible: un rastro almacenado, un rastro memoria (Fontcuberta, 1997: 78)". Pero en 2011, el mismo autor la redefine: "En estas fotos la voluntad lúdica y autoexploratoria prevalece sobre la memoria. Tomarse fotos y mostrarlas en las redes sociales forma parte de los juegos de seducción y los rituales de comunicación de las nuevas subculturas urbanas postfotográficas de las que, aunque capitaneadas por jóvenes y adoles- 
centes, muy pocos quedan al margen. Las fotos ya no recogen recuerdos para guardar sino mensajes para enviar e intercambiar: se convierten en puros gestos de comunicación..." (Fontcuberta, 2011: s/n). Luego de la revolución digital y móvil de las redes de usuario, la fotografía ya no es memoria, es instante. Ya no almacena, sino que muestra: "soy yo", "estoy/estuve aquî", "compré esto", "vinimos acá". La fotografía compartida en redes sociales es un indicio efímero de millones de momentos intrascendentes si se considera aisladamente, pero puede aportar nuevo conocimiento sobre los espacios, los cuerpos que los ocupan, las estéticas, los modos de vida y el significado de la práctica fotográfica en un momento y lugar dados si se estudian colectivamente.

Instagram es una red social para la publicación de fotografías tomadas con teléfonos celulares. Fue inaugurada en 2010 y a los dos meses de su lanzamiento, tenía un millón de usuarios. En sus inicios fue desarrollada solamente para iPhone, aunque en 2012 salió al público la versión abierta para Android. En ese mismo año fue comprada por Facebook por un billón de dólares. Esta adquisición le permitió a la empresa el ingreso al mercado de contenidos producidos por dispositivos móviles, aunque en ese momento no quedaba claro cómo se generarían las ganancias de la plataforma fotográfica (Michel y Holpuch, 2012). A fines de 2015 la plataforma tenía cuatrocientos millones de usuarios activos, que habían subido a seiscientos millones en diciembre de 2016 (Statista, 2017a). En 2016 sus ingresos por publicidad fueron de 1.48 billones de dólares. Para 2017 se prevé que aumente al doble (Statista, 2017b). A diario se suben unos ochenta millones de fotos, que reciben unos trescientos cincuenta billones de visualizaciones por día (Streatfield, 2015). Los filtros de imagen, las etiquetas que agrupan las fotografías en espacios de significación compartidos, y la posibilidad de geolocalizarlas son los valores estéticos que diferencian a Instagram de otras redes sociales visuales.

\section{FOTOGRAFÍA URBANA COMPARTIDA Y MÉTODOS DIGITALES: UN ESTADO DEL ARTE}

La etnografía digital (Hine, 2005) ha sido pionera en determinar que el entorno digital es un sitio apropiado para estudiar las prácticas culturales en línea. Aunque en un primer momento de las interacciones comunicativas en Internet previas al auge de las redes sociales se consideraron diferentes de las sucedidas cara a cara, las investigaciones actuales entienden que las prácticas digitales no están separadas de la vida social, sino que se encuentran embebidas en la vida social y cotidiana (Hine, 2015). La etnografía virtual difiere de los métodos digitales en que la primera se enfoca en las prácticas de los usuarios y los segundos en objetos digitales nativos, o datos, que son estudiados siguiendo la lógica del medio en que son producidos con instrumentos digitales ( Rogers, 2009). Actualmente existe una controversia entre ambos métodos (Marres, 2017). El abordaje de la fotografía compartida es posible desde ambas perspectivas. En esta oportunidad consideramos el abordaje basado en datos dada su novedad y la necesidad 
de poner en juego los métodos para considerar su alcance. Esto no invalida la posibilidad de abordar la temática desde perspectivas cualitativas.

La fotografía urbana compartida en plataformas sociales ha sido estudiada previamente desde varias perspectivas, tanto centradas en prácticas como en datos. Dentro de la primera línea, Van Dijck (2010 y 2016) aborda desde una perspectiva sociotécnica las disposiciones y los usos sociales de la plataforma Flickr, entendiéndola como una plataforma comunitaria sostenida por el amor que sus miembros le tienen a la fotografía, y como proveedora de nuevas fuentes de imágenes para las agencias de noticias. Gómez Cruz (2012) estudia desde un punto de vista etnográfico las prácticas fotográficas digitales en la vida cotidiana. Destaca el carácter socializador de la práctica de la fotografía digital compartida, ya que en su ejercicio se comparten intereses comunes sobre una temática, la posesión de un mismo equipo fotográfico, o el interés turístico o local sobre una determinada ciudad al fotografiarse. Los grupos que se configuran en torno a la fotografía compartida ponen de relieve su valor socializante.

Dentro de la segunda línea, basada en datos, el estudio de Hochman y Manovich (2013) sobre representaciones de ciudades en Instagram es pionero en abordar la temática desde el análisis de datos. Los autores exploran más de dos millones de fotografías de trece ciudades compartidas en Instagram para demostrar cómo los datos y metadatos de contenidos compartidos pueden usarse para estudiar patrones en múltiples escalas. En su trabajo los autores sugieren que los medios sociales pueden ser usados para la lectura de eventos sociales y culturales y oponen el propósito de Google Earth al de Instagram. Mientras que en el primero sus esfuerzos documentales son presentados como objetivos y desafectados por medio del uso de fotografías satelitales, en el segundo resuenan como experiencias más auténticas y personales.

Highfield y Leaver (2016), por su parte, proponen el estudio Instagram partiendo de sus etiquetas, haciendo extensiva una metodología previa aplicada a Twitter. Las fotografías son estudiadas para identificar las percepciones sociales sobre los límites de la vida: el nacimiento y la muerte. Manovich (2016) estudia la fotografía de ciudades en Instagram a partir de la emergencia de patrones estéticos en un gran set de datos, identificando tres clases de estilos: casual, producido y profesional.

\section{CONSIDERACIONES ÉTICAS SOBRE EL ESTUDIO DE LA FOTOGRAFÍA COMPARTIDA}

Nuestro conjunto de datos se compone de fotografías que pueden ser visualizadas públicamente al navegar por las etiquetas desde la interfaz de la plataforma. Según las políticas de uso de Instagram (2013) si los perfiles son privados, las fotografías no pueden ser visualizadas. Por consiguiente no han sido recolectadas. Dado que las leyes de copyright no cubren ningún objeto que esté en el dominio público (Hewson, 2016), el carácter público de las fotografías (Instagram, 2013) anula todo conflicto legal. 
Debido a la técnica utilizada para su recolección la solicitud de consentimiento informado para el uso de las imágenes no resulta posible. Este estudio sigue los lineamientos éticos de AoIR (2012), la British Psychology Society (2013) y Hewson (2016). En este trabajo se protege el derecho a la privacidad por cuanto no hay manera de relacionar las imágenes estudiadas con sus creadores. Las fotografías se estudian como obras públicas y publicadas en un medio de comunicación, no como parte de la historia o la psicología de uno o más sujetos. El control sobre la muestra se resguarda en función de las siguientes decisiones: no se exponen imágenes de personas, no se recolectan muestras de perfiles privados, y se asume que el etiquetado de fotografías expresa la intención de visibilidad de las mismas por parte de los usuarios. La temática seleccionada no es controvertida, no presenta conflictos sociales ni morales, ni predispone a la discordia entre grupos controversiales. Tampoco se realizan juicios morales o estéticos sobre las imágenes estudiadas, considerándoselas siempre como parte de una experiencia relevante para ser comprendida en términos culturales. Consideramos que el estudio aporta elementos metodológicos y empíricos para el estudio de la fotografía compartida sin comprometer en ningún nivel la privacidad de los usuarios productores.

\section{COMPOSICIÓN DEL CORPUS: DATOS Y METADATOS}

La construcción del corpus responde al concepto de small data (Rogers, 2013), surgido en oposición al de big data. El Diccionario de Inglés de Oxford define big data como «datos de un tamaño muy grande, típicamente en la medida en que su manipulación y administración presentan retos logísticos significativos» ("big data" y Press, 2014). En cambio el concepto de small data considera un conjunto de datos que se encuentra al alcance de los investigadores sociales sin requerir equipamiento fuera de lo común para analizarlo con métodos digitales. Burgess y Bruns (2015) destacan que una cantidad importante de investigación sobre medios sociales usa conjuntos de datos comparativamente pequeños pero ricos. Trabajar con small data implica el empleo de un conjunto de datos que el investigador social puede organizar por sus propios medios, pero aplicando técnicas de procesamiento afines a las empleadas en los estudios de big data.

Teniendo en cuenta las afirmaciones citadas, recolectamos un conjunto de 5.185 imágenes (Tabla 1) publicadas en Instagram durante la primera semana de octubre de 2016. Para establecer la validez numérica de la muestra usamos una calculadora que nos permitió establecer un índice de confiabilidad del 95\% sobre el corpus obtenido.

En este estudio no entendemos los datos como naturalmente dados. Aunque parezca objetivo, todo dato es una construcción metodológica moldeada por las limitaciones del método que se emplea para obtenerlo y la información de la que el dato es portador. A continuación exponemos la construcción de nuestro corpus de datos.

El conjunto de datos fue recolectado mediante la técnica denominada scra- 
ping. Ésta es una técnica específica del medio digital que permite la recolección automática de datos on-line y posibilita la investigación basada en datos (Marres y Weltevrede, 2013). Debido a que las plataformas sociales suelen cambiar sus políticas de acceso a la información, debe asumirse que el scraping es un proceso dinámico y cambiante, y que muchas veces los programas o las plataformas que proveen sus servicios suelen dejar de funcionar o cambiar sus condiciones de uso. Específicamente recurrimos a un tipo scraping denominado screen scraping interface, un programa que simula ser un humano y "lee" la pantalla almacenando los datos en listas que pueden ser procesadas automáticamente" (Fulton, 2014). Se realiza a través de programas simples que automatizan el proceso y convierte el HTML en datos.

\begin{tabular}{lll}
\hline Etiqueta & & Imágenes recolectadas \\
\hline & \#madrid & 1.110 \\
& \#cdmx & 2.072 \\
& \#buenosaires & 2.003 \\
Total & 5.185
\end{tabular}

Tabla No 1. Cantidad de imágenes recolectadas por etiqueta

El corpus estudiado incluye no sólo las imágenes, sino todos metadatos que forman parte de su publicación: descripciones textuales, reacciones de usuarios, fechas de publicación, y cantidad de comentarios. Mientras que a cada fotografía le corresponde un archivo de imagen en formato .jpg, los metadatos se almacenan como datos estructurados en un solo archivo en formato .csv organizado en filas y columnas, en la que cada fila corresponde a una imagen y cada columna corresponde a un metadato.

\section{LA APROXIMACIÓN DISTANTE COMO MÉTODO DIGITAL}

Interrogamos el corpus a través de un conjunto de técnicas que denominamos genéricamente aproximación distante. En el campo de los estudios literarios cuantitativos Moretti $(2007,2015)$ distingue dos tipos de lecturas: la distante y la cercana. La primera es de tipo exploratoria, opera con la masa, la generalidad y los hechos comunes. El investigador identifica patrones de regularidad y frecuencia, grandes agrupamientos o clústers, ciclos temporales, y estructuras reticulares (Manovich, 2009). Mientras que lo distante opera con lo masivo, la generalidad y los hechos comunes, lo cercano lo hace con lo particular, lo excepcional y lo fuera del común. Al compartir con los textos literarios una dimensión significante, los objetos digitales admiten y demandan en un primer momento una aproximación distante exploratoria. Ésta permitirá abrir la caja negra de un conjunto de datos en los que, a primera vista, nada puede ser identificado, visualizado, ni relacionado. 
La aproximación distante se basa además en la analítica de datos, definida por Gandolmi y Heider (2015) como el conjunto de técnicas usadas para volverlos inteligibles y otorgarles un sentido. También se sirve de diferentes enfoques basados en colecciones de datos y desarrolladas por escuelas de investigación actuales, especialmente por la Iniciativa de Métodos Digitales (Rogers, 2013) y la Iniciativa de Estudios del Software (Manovich, 2011a).

Rogers (2015) define los métodos digitales como una aproximación al estudio de la Web basada en un dataset, o conjunto de datos que acompaña al giro computacional en las ciencias sociales y humanidades (Berry, 2011). Los métodos digitales no son una colección de herramientas, sino, que constituyen "un diseño de investigación donde toman parte fenómenos, objetos, campos de observación, marcos teóricos, categorías, comunidades, sujetos o prácticas, digitales, y donde se generan, utilizan, almacenan, analizan o modelan datos digitales" (Ortega y Caloca, 2017: 2). Su objetivo es diagnosticar el cambio cultural y las condiciones sociales con Internet. El punto de partida de su programa de investigación es el reconocimiento de Internet no sólo como objeto de estudio, sino como fuente para estudiar la vida social (Rogers, 2009: 3).

Caracterizamos la aproximación distante como una metodología mixta de investigación (Creswell, 2014) que combina el análisis cuantitativo, el uso de software de procesamiento de datos textuales y numéricos y la interpretación de resultados. Considera a las fotografías compartidas en su dimensión tanto digital como cultural.

Propone interrogar los datos y metadatos desde diferentes técnicas basadas en software. Aplicamos el análisis de contenido (Rose, 2016) y la analítica visual (Thomas y Cook, 2005 Manovich, 2011b) al corpus fotográfico con el fin de identificar temáticas recurrentes y patrones estéticos. Empleamos la analítica textual (Moreno y Redondo, 2016) para identificar las palabras frecuentes en las descripciones de las fotografías. El análisis de redes (Venturini, Jacomy y Carvalho, 2015) nos fue útil para establecer conexiones y clústers o agrupamientos entre etiquetas co-ocurrentes. Finalmente estudiamos las reacciones en relación al consumo activo de las fotografías una vez publicadas en la plataforma denominado engagement en la literatura anglosajona (Turner, 2014 y Rogers, 2016).

Los resultados del trabajo con las mencionadas técnicas se materializaron en visualizaciones, definidas por Manovich (2011b) como la comunicación de datos abstractos a través de interfaces gráficas cuyo objetivo es el de develar la estructura de un conjunto de datos, desconocida antes de ser visualizada. Éstas fueron interpretadas en función de patrones, recurrencias y agrupamientos emergentes donde pudimos identificar a qué representaciones y prácticas culturales se asocia cada una de las tres ciudades. 


\section{ANÁLISIS DE CONTENIDO}

A fin de obtener una visión general de la composición del corpus, ejecutamos un análisis de contenido. Rose (2016) lo considera un método cuantitativo que consiste en contar la frecuencia de aparición de ciertos elementos visuales en una muestra claramente definida de imágenes. Para materializarlo usamos la técnica de etiquetado manual.

En principio encontramos que el objeto "fotografía" no se dejaba definir fácilmente, ya que existen en el corpus una cantidad de imágenes no fotográficas, por ejemplo "posters" publicitarios, dibujos digitales y cuadros de texto. La fotografía compartida es un puro gesto de comunicación donde algo se muestra o se exhibe. Pero la función esencial de un volante publicitario es la de la persuasión a comprar un producto o usar un servicio, por lo que consideramos a ese conjunto de imágenes como "Imágenes Diversas", y así las etiquetamos en nuestro análisis de contenido.

Clasificamos el resto de las imágenes en cuatro categorías según su contenido: Animales, Espacios, Objetos y Personas. Las decisiones se tomaron teniendo en cuenta la interpretación composicional, definida por Rose (2016) como una aproximación global a las imágenes a partir de varios elementos de forma y contenido, por ejemplo sus colores, su tema, el foco, el plano, la atmósfera, la expresividad, y las relaciones que se entablan entre ellos. Para desambiguar si una imagen correspondía a la categoría "Espacios" o a la categoría "Personas", definimos su categorización en relación al foco. En el caso de las personas por ejemplo, al quedar éstas por delante del espacio, el foco se posa sobre ellas y el espacio queda en segundo plano, por lo que nos decidimos insertarla en la categoría de "Personas".

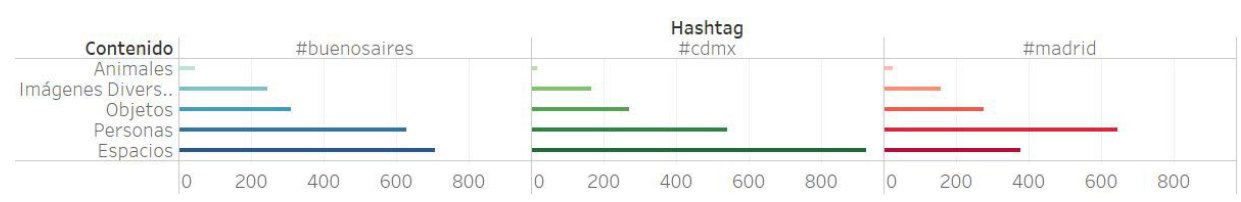

Gráfico 1 Total de registros por tipo de contenido desglosado por etiqueta.

Advertimos que existe un patrón temático que se altera apenas en la última fila del gráfico. En el caso de \#madrid, la cantidad de fotografías de "Personas" superan a la de "Espacios". Pero en \#buenosaires el mismo caso presenta inclinación hacia la equiparación entre las dos categorías. Este patrón indica una tendencia acerca de cómo se experimenta una ciudad, si en base a la experiencia de estar allí o en relación a la contemplación de sus escenarios. 


\subsection{Analítica visual y textual: temática y estética de las ciudades}

A fin de identificar patrones temáticos combinamos dos tipos de procesamiento. Primero usamos la técnica de recuento de palabras propia de la analítica textual. Moreno y Redondo (2016) la definen como un modo de leer que reúne lo cuantitativo con lo cualitativo a partir de un proceso automatizado de extracción de información. Por un lado es cuantitativo en tanto identifica la frecuencia de aparición de palabras en un texto o en varios. Por otro es cualitativo en cuanto devela automáticamente los contextos textuales que rodean a una palabra determinada. En este caso realizamos un recuento de palabras frecuentes presentes en las descripciones que los usuarios producen sobre sus fotografías al publicarlas. Las palabras frecuentes muestran temáticas recurrentes diferentes para cada ciudad.

\begin{tabular}{lrlrlr}
\hline \multicolumn{1}{c}{ Buenos Aires } & \multicolumn{3}{c}{ México } & & \multicolumn{2}{c}{ Madrid } \\
\hline argentina & 1339 & city & 101 & spain & 289 \\
loves & 145 & mextagram & 77 & españa & 150 \\
igersbsas & 144 & amanecer & 73 & barcelona & 133 \\
photography & 144 & love & 73 & paris & 128 \\
city & 143 & photography & 73 & london & 112 \\
photo & 130 & sunrise & 73 & love & 111 \\
love & 128 & architecture & 72 & fashion & 100 \\
travel & 118 & morning & 71 & newyork & 100 \\
igers & 117 & igers & 70 & berlin & 92 \\
palermo & 106 & ciudaddemexico & 64 & miami & 88 \\
bsas & 105 & radiohead & 64 & travel & 78 \\
picoftheday & 105 & picoftheday & 63 & picoftheday & 67 \\
captures & 102 & vsco & 59 & istanbul & 66 \\
instagood & 88 & ciudad & 58 & and & 62 \\
photooftheday & 88 & instagood & 58 & dubai & 62 \\
fashion & 86 & travel & 56 & losangeles & 58 \\
instagram & 86 & photo & 53 & happy & 55 \\
arte & 83 & arquitectura & 49 & tokyo & 54 \\
igworldclub & 82 & nofilter & 49 & architecture & 52 \\
southamerica & 80 & vscocam & 49 & moscow & 52
\end{tabular}

Tabla 2. Rango de las 20 palabras más frecuentes por ciudad que aparecen en la descripción de las fotografías.

\#buenosaires presenta mayoría de palabras relacionadas con la práctica de la fotografía compartida: \#igersbsas" apócope de Instagram Buenos Aires, \#pho- 
tography, \#ig_buenosaires, \#photo, con el viaje: \#city, \#travel, \#southamerica, así como con experiencias del orden de lo estético y el consumo: \#fashion, \# art.

En \#cdmx la práctica de la fotografía como comunidad es importante: la etiqueta \#mextagram refiere a los usuarios mexicanos de Instagram. Una particularidad de México es la frecuencia de palabras que refieren amaneceres y atardeceres: \#morning, \#sunrise, \#amanecer, \#sky.

La particularidad de \#madrid consiste en que las palabras frecuentes la insertan en el contexto de múltiples ciudades, tanto europeas como americanas: Barcelona, París, Londres y otras. En esa red la ciudad adquiere un valor global, en contraste con la ciudad de México, insertada en su contexto local. En este caso los términos que refieren a la práctica de la fotografía compartida ocupan un lugar secundario.

Como puede verse en la Tabla 2, las palabras frecuentes de cada ciudad comparten significados y connotaciones y se organizan en redes semánticas. En \#buenosaires, la experiencia urbana y del viaje, en \#cdmx el retrato de la ciudad, sus colores y arquitectura, en \#madrid la pertenencia de la ciudad a una red global donde la promoción del consumo de objetos y el uso publicitario y comercial del etiquetas, desdibujan la representación de la ciudad como espacio público. La palabra love es común a las tres ciudades, y puede denotar tanto sentimientos de empatía y afecto como la promoción de objetos de consumo, que se supone los usuarios "amarían".

Por otro lado el inglés es el idioma más usado. Los usuarios describen sus fotografías con una especie de "pidgin", mezcla de inglés y español sea para lograr la mayor visibilidad de sus producciones, o como código propio de la fotografía compartida.

Con el propósito de indagar si los los patrones temáticos referidos se relacionan con los patrones cromáticos del conjunto de fotografías realizamos un montaje con el software Image Plot (Manovich, s/f), que permite ordenar una colección de imágenes en una sola visualización. En este caso la organizamos sobre la medición del promedio de matiz, en el eje horizontal, y del promedio de brillo, en eje vertical. Para distinguir los colores propios de cada ciudad hemos extraído las tonalidades de cada una de ellas. Usamos el software en línea Color, de Adobe, con el que identificamos cinco variaciones (Gráfico 1): colores plenos, colores claros, apagados, intensos y oscuros.

En una primera mirada la escala cromática de las tres ciudades parece similar: la mayor cantidad de fotografías contienen más tonos cercanos a los rojos y los azules y menos a los verdes. Es por eso que el lugar que ocupa el verde, hacia el centro del gráfico, se ve desprovisto de imágenes, sobre todo en \#madrid, lo que nos lleva a suponer que los espacios públicos verdes como plazas o parques se encuentran poco representados en Instagram. Al observar los montajes en gran escala, podemos relacionar las tonalidades con temáticas. Las rojas y anaranjadas responden a temáticas heterogéneas, pero el general responden a la representación de personas, por su color de piel, comida y objetos. En la visualización de \#madrid el rojo ocupa más espacio que en las otras dos ciudades, ya que la cantidad de fotografías de personas es mayor a la de espacios. El patrón cromático 
devela que la comida y las personas se identifican más con las ciudades que los espacios públicos verdes. El color azul es recurrente en las tres visualizaciones, pero sólo en \#cdmx el cielo es una temática fotográfica en sí misma. En \#madrid y \#buenosaires aparece como trasfondo de edificios emblemáticos o monumentos, es decir, como complemento de las temáticas fotográficas que buscan la estética contemporánea en las arquitecturas.
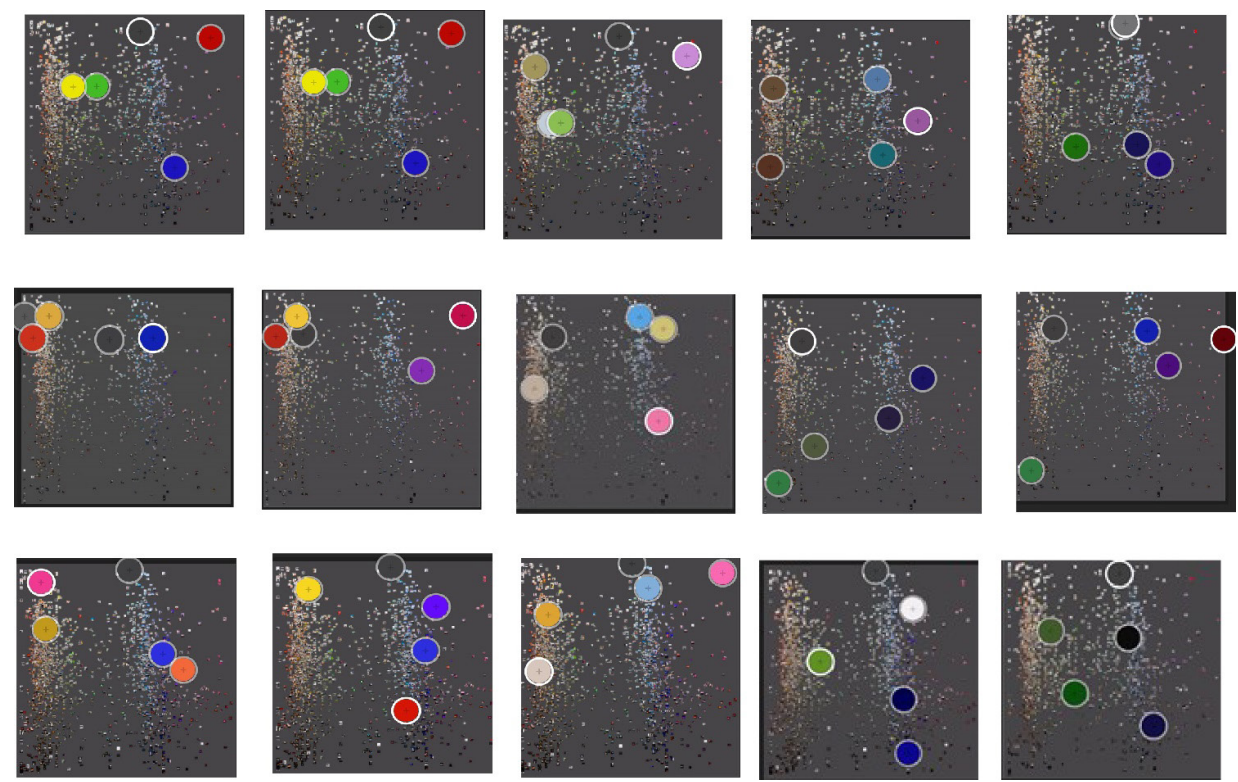

Imagen 1. Extracción de la paleta de colores de cada ciudad. De arriba hacia abajo: \#buenosaires, \#madrid, \#cdmx

\subsection{Análisis de etiquetas: visualizar una red}

Los usuarios clasifican sus imágenes a través de las llamadas "folksonomías": un modo de categorizar y encontrar información a partir de etiquetas generadas colaborativamente (Noruzi, 2006). Las etiquetas son metadatos generados por los usuarios que agregan valor, sentido y contexto a los datos, organizándolos en redes abiertas y navegables. Los usuarios de Instagram suelen colocar más de una etiqueta a su fotografía, llegando a veces a convertir cada palabra en una etiqueta con sólo anteponerle el símbolo "almohadilla". Varias motivaciones llevan a los usuarios a etiquetar sus fotos: organizarlas temáticamente, proveer información contextual (Oh, Lee et al., 2016) y adquirir mayor visibilidad para sus producciones, ya que los usuarios pueden navegar las producciones de una etiqueta colocando su nombre en el explorador de Instagram. Nuestra hipótesis es que además de estos usos, en Instagram el etiquetado co-ocurrente cumple una 
función socializadora a través del que se comparten intereses temáticos similares, se construye la pertenencia a un grupo de usuarios que usan etiquetas recurrentes, y se intenta captar la atención de los usuarios que exploran la etiqueta.

Denominamos co-ocurrentes a todas las etiquetas que se usan en la descripción de una misma fotografía. Por ejemplo, la siguiente enumeración de etiquetas co-ocurre en la misma fotografía: "\#SinFiltro \#NoFilter \#UNAM \#modernism \#architecture\#archilovers \#architectureporn\#Arquitectura\#tv_pointofview \#rsa_outdoors \#rsa_architecture \#CDMX \#CiudaddeMexico \#MexicoCity \#MEXICODF \#DF \#Mexico \#mextagram \#paisajedfeo \#mexicourbano \#Sky \#urban \#instagood \#instamood \#ig_mexico \#vscocam".

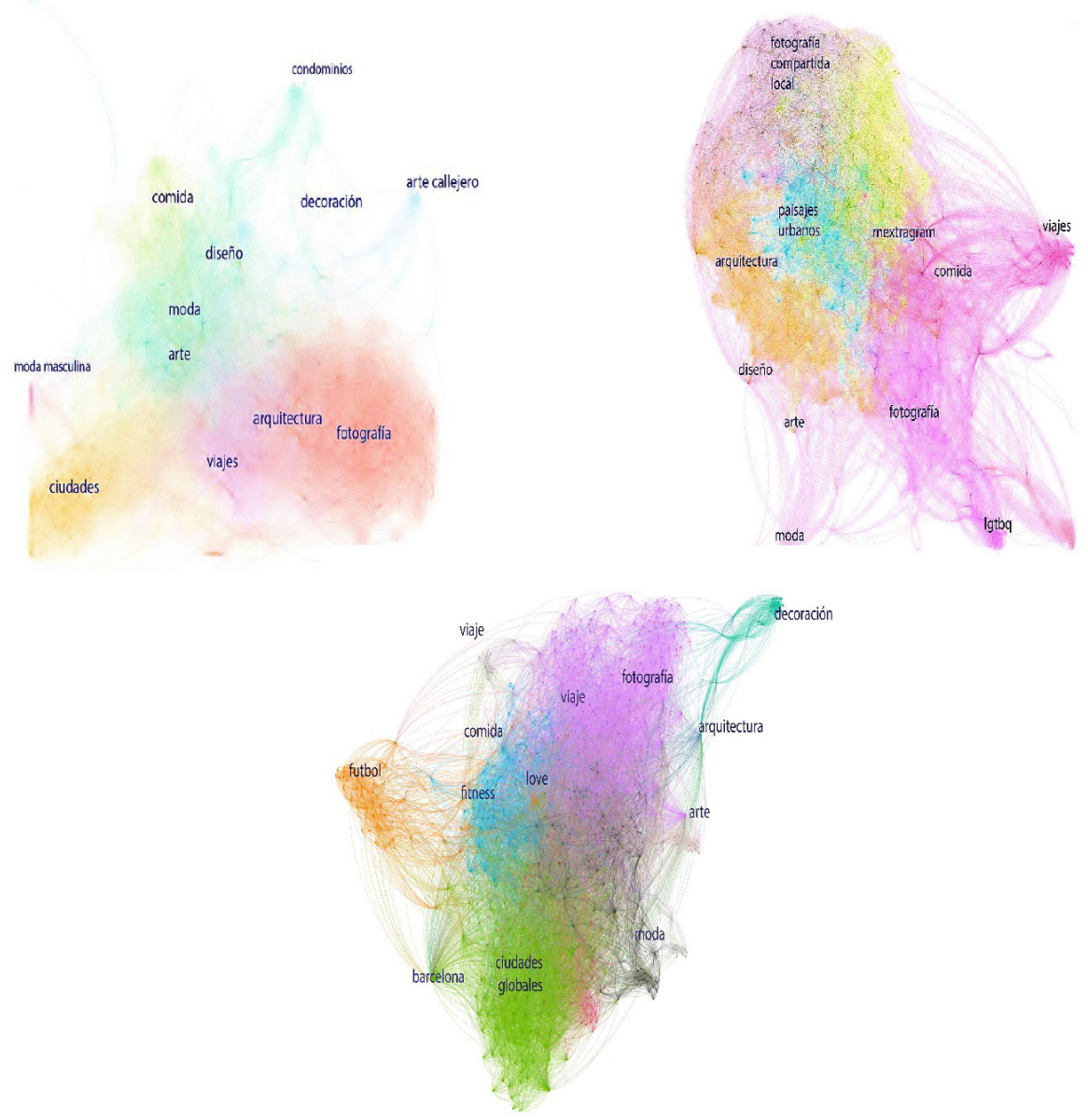

Imagen 2 Clústers de etiquetas en \#buenosaires, \#cdmx (de izq. a der.) y \#madrid (abajo) 
Empleando el software Gephi visualizamos la co-ocurrencia de etiquetas en una red (Borra y Rieder, 2014) donde los nodos están formados por etiquetas y los enlaces por cada fotografía publicada (Imagen 2). Luego graficamos clústers o grandes grupos de comunidades. En los tres casos obtuvimos redes densas. Esto quiere decir que sus nodos se encuentran enlazados estrechamente unos con otros ya que, como evidenciamos en el análisis textual (Tabla 2), la frecuencia de uso de las etiquetas es alta. La densidad de la red también implica que los usuarios usan un conjunto limitado de etiquetas. Si el éste fuera mayor los nodos no estarían conectados entre sí y los grafos se verían dispersos.

El análisis de red, en la Imagen 2 se correlaciona con el análisis temático en los tres casos, pero agrupa las etiquetas en clústers que permiten observar cuáles son las temáticas y experiencias recurrentes. El análisis muestra que cada ciudad se encuentra inmersa en una red que le otorga contexto y significado.

El clúster más importante de \#buenosaires presenta mayoría de etiquetas relacionadas con la práctica de la fotografía compartida: \#igersbsas, \#photography, \#igbuenosaires, \#photo. Los que le siguen responden a estilos de vida modernos y estilizados: arte, moda, diseño, comida, decoración. Luego siguen los clústers de viajes y ciudades.

El gráfico de \#cdmx también contiene agrupamientos importantes en relación a la fotografía compartida, pero con una particularidad: en el cuadrante inferior izquierdo identificamos un clúster formado por etiquetas globales: \#picoftheday, \#instagood, \#photography, mientras que en el cuadrante superior izquierdo se evidencia una red muy importante de etiquetas locales agrupadas en torno al nodo \#mextagram: \#mexigers, \#mexicanoscreativos, \#igerscdmx y otros. A partir de éstas puede suponerse una comunidad mexicana de fotografía compartida. Estos clústers son muy cercanos, y por lo tanto guardan relación, a otros agrupamientos de temática urbana: el centro histórico, el emblemático edificio de la Torre Latina, la Catedral, el Metro. También allí se encuentran los amaneceres y atardeceres, que aparecen recurrentemente en los Tabla 2 y la Imagen 2. A su izquierda se encuentra el clúster de arquitectura, que es importante en tamaño y refiere a los centros de modernidad de la ciudad: el museo Soumaya, los rascacielos, las luces y las vistas aéreas. Pero también encontramos allí modos de mirar: abstracción, geometría, líneas, perspectivas. A diferencia de lo que sucede con \#buenosaires y \#madrid no emerge un clúster importante de ciudades globales, y la moda, el arte y el diseño ocupan un lugar secundario.

Por el contrario, el agrupamiento más importante de \#madrid es el de las grandes ciudades y el nodo de mayor peso es \#love. Este nodo se encuentra cercano al clúster de estilos de vida, viajes y cultivo del cuerpo. Asimismo el fútbol ocupa un clúster importante debido al equipo del mismo nombre que le otorga la etiqueta una identidad local. En este caso la referencia a la fotografía compartida es secundaria respecto de otras ciudades, pero se encuentra relacionada con el viaje, la arquitectura y el arte, que en esta ciudad llegan a ser nodos de peso pero no clústers como era el caso de \#cdmx.

Los gráficos de red evidencian maneras múltiples de representar y experimentar una ciudad: \#buenosaires a través de la experiencia, \#cdmx, a través de 
la arquitectura y los paisajes urbanos, y finalmente \#madrid como escaparate virtual y centro de consumo de moda, viajes y estilos de vida.

Analítica de reacciones: diferencias entre producción y recepción de las imágenes

Es sabido que los medios sociales disuelven los límites entre producción y recepción (Scolari, 2008 y Jenkins, 2009), ya que las audiencias participan activamente en la construcción de contenidos así como en su valoración. Esta condición permite que las dos esferas funcionen simultáneamente dentro de la plataforma: la instancia de producción se expresa en la publicación de fotografías y la de recepción a través de las marcas valorativas de las audiencias. La participación de las audiencias puede estudiarse cuantificando estas reacciones. En esta oportunidad la determinamos sumando todas las reacciones que recibe de cada fotografía a fin de identificar qué contenidos reciben mayor valoración.

En ese sentido el Gráfico 2, donde se muestran las reacciones en relación al contenido, revela un patrón similar al de publicaciones por contenido visualizado en el Gráfico 1. Podemos deducir de ellos que la cantidad de reacciones es proporcional a la cantidad de contenidos producidos. Este patrón puede indicar que existe una retroalimentación entre producción y recepción: lo que más se publica recibe más reacciones, y a la inversa, lo que recibe más reacciones es lo que más se publica. Se necesitan estudios más profundos para verificar esta hipótesis.

Dentro de este nivel hemos observado otro patrón común a las tres ciudades: el uso publicitario de la imagen recibe más reacciones. En \#madrid, una empresa que ofrece servicios reparadores del cabello con base en Estambul muestra los resultados de un trasplante de cabello, en \#buenosaires la cuenta de una revista especializada en motocicletas promociona un nuevo modelo, y en \#cdmx , la cuenta de una artista que vende arte digital erótico exhibe una obra digital. Estas imágenes reciben más del doble de las reacciones de la segunda en la lista, evidenciando la potencialidad publicitaria de la plataforma, pero también poniendo en cuestión la espontaneidad de las reacciones, que podrían deberse a campañas de márketing donde las reacciones se automatizan mediante bots y algoritmos (Jenssen, 2017), fenómeno que debe ser estudiado con mayor profundidad.

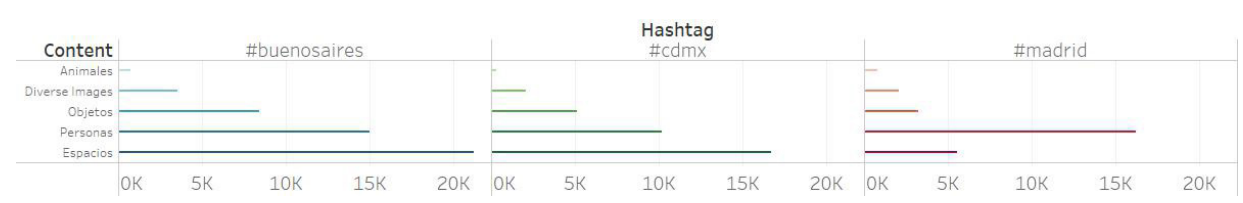

Gráfico 2. Total de reacciones por tipo de contenido, desglosado por etiqueta.

Si bien a nivel de un análisis general de contenido el patrón de publicaciones es similar al de reacciones, su particularización dentro de cada categoría puede revelar patrones diferentes.

Por ejemplo, dentro de la categoría "Espacios" de \#cdmx se produce una diferencia entre producción y recepción. La visión pictórica de la ciudad representada en las tomas de amaneceres y atardeceres son contenidos recurrentemente 
publicados, según se visualiza en la Tabla 2. Sin embargo, como se evidencia en la Imagen 3, es el aspecto arquitectónico moderno de la ciudad de México el que recibe mayores reacciones por parte de los usuarios. Comprobamos así la variación entre el acto de tomar una fotografía y el de mirarla. El primero refiere a una visión paisajista y colorista del entorno urbano, derivada del lenguaje pictórico y de la búsqueda de colores: amaneceres, atardeceres, paisajes. En cambio el segundo se vincula a valores propios de la modernidad: arquitectura, diseño, práctica fotográfica. Resaltan las edificaciones modernas y las luces de neón, símbolos urbanos y de modernidad. De este modo, entre la producción y el consumo se produce un desplazamiento de lo pictórico a lo fotográfico, de paisajismo a la modernidad.

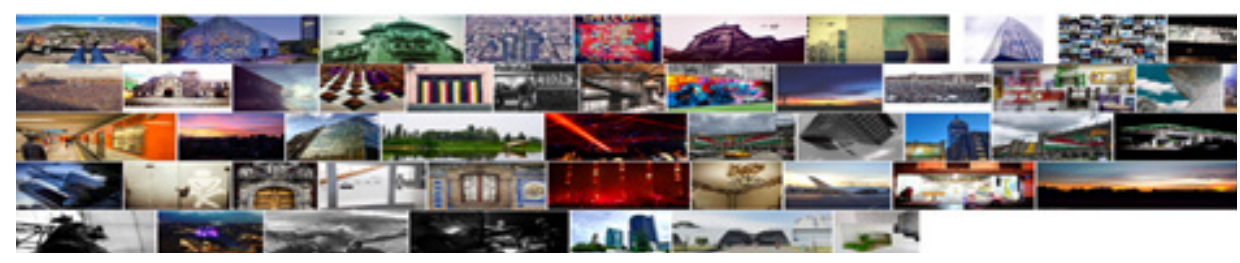

Imagen 3. Montaje de las 50 fotos con mayor cantidad de reacciones categorizadas como Espacios de \#cdmx.

El análisis de reacciones permite además diferenciar tipos de fotografía en Instagram. Manovich (2016) distingue tres grupos: las casuales, tomadas instantáneamente por aficionados, las diseñadas, que pueden ser tomadas tanto por aficionados como por profesionales pero evidencian estrategias de pre o post producción, y las profesionales, publicadas por fotógrafos que buscan darse a conocer. En \#cdmx, las fotos con mayores reacciones entran en los dos últimos grupos, mientras que la mayor parte de la producción estudiada entra en el primero. Si se observa de izquierda a derecha la Imagen 3, la primera fotografía corresponde a una celebridad, la segunda a un estudio profesional de arquitectura, la tercera a uno de fotografía, al igual que la sexta y la séptima. La cuarta fue tomada por un fotógrafo profesional desde el aire. Otras denotan el uso de cámaras y angulares profesionales. La mayoría de ellas se distingue bastante de la foto casual, y buscan retratar esencialmente la estética moderna de la ciudad.

La fotografía con más cantidad de reacciones en \#cdmx, cuya función no es publicitaria, cumple todas las características de la post-fotografía: figura en la cuenta de una celebridad, es una toma subjetiva, se ve el cielo en el fondo y cumple funciones de autopromoción. 

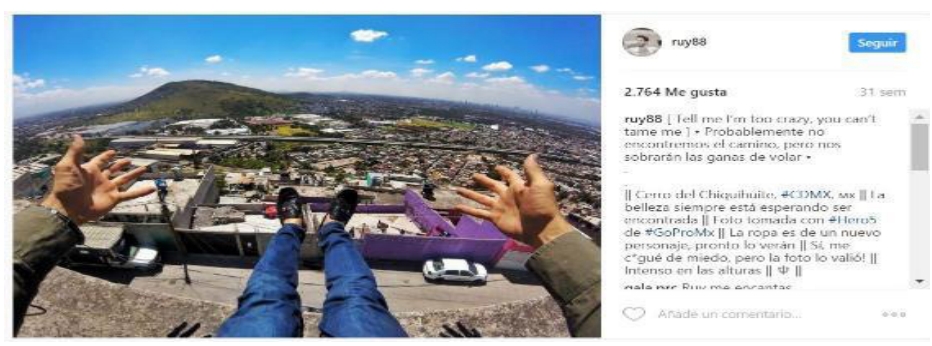

Imagen 4. Fotografía etiquetada como \#cdmx con mayores reacciones entre las categorizadas como "Espacios"

\section{DISCUSIÓN: ALCANCES Y LIMITACIONES DE LA METODOLOGÍA}

A partir del estudio realizado podemos observar que la aproximación distante resulta efectiva para abrir la caja negra de los medios sociales y mapear los principales temas y patrones estéticos de la fotografía compartida, aunque este abordaje debe en un futuro someterse a mayor investigación empírica y profundización epistemológica sobre varios de sus componentes.

La investigación con métodos digitales se encuentra limitada por el acceso a los datos que las plataformas sociales proveen o restringen, y por las técnicas disponibles a los investigadores. Diferentes estudios señalan que las plataformas sociales condicionan y sesgan las interacciones de los usuarios (van Dijck, 2016 y Tufekci, 2014). Todavía no resulta claro el modo en que estos sesgos funcionan en Instagram por lo que no han podido ser considerados en este estudio.

En este estudio no se pudo acceder a todos los metadatos vinculados a la fotografía sino a un conjunto limitado de ellos que permitió trabajar con ciertas técnicas, pero no con otras, por ejemplo de geolocalización o análisis de sentimientos. En los métodos digitales las posibilidades de la investigación se encuentran limitadas por el acceso a los datos, que en la mayoría de los casos las plataformas son resistentes a proveer.

Las técnicas de investigación de datos, la comprensión del modo en que funciona el software que se emplea en el procesamiento de los datos y metadatos necesitan de mayor investigación. Las técnicas de analítica visual son complejas de aplicar sin el equipamiento adecuado, por ejemplo video walls de alta definición que permitan visibilizar patrones con precisión (Manovich, 2012). También resulta dificultosa su adaptación a los formatos de publicación impresa.

Todavía no se ha profundizado lo suficiente en la comprensión de las vinculaciones entre los objetos digitales y la vida social. Faltan estudios teóricos y empíricos que nos permitan entender más profundamente cómo deben ser interpretadas las trazas digitales en relación a interacciones sociales como las estudiadas. Por el momento podemos proponer que cada estudio de datos digitales 
construye una teoría fundada acerca de cómo deben leerse esos mismos datos en relación a las sociedades donde tienen lugar.

La investigación en métodos digitales no se encuentra todavía estabilizada en los estudios sociales iberoamericanos. El estudio de las mediaciones en Latinoamérica siempre ha relacionado la práctica cultural con las estructuras sociales, identificando en los consumos culturales o bien prácticas de subordinación, o bien de resistencia (Martín-Barbero, 2001). Hace falta estudiar en qué medida los métodos digitales pueden contribuir a responder estos interrogantes fundamentales para los estudios sociales y de la comunicación.

Se remarca el carácter exploratorio de este estudio. Su profundización podría abordar los límites entre el espacio público y el espacio privado, los lugares relevantes para cada una de las ciudades, el modo en que las personas eligen mostrarse en las etiquetas urbanas. Estas temáticas pueden arrojar nuevo conocimiento sobre la vida contemporánea

\section{CONCLUSIONES: PRINCIPALES HALLAZGOS EMPÍRICOS}

El corpus estudiado devela formas diferenciadas de representación que distinguen a cada una de las tres ciudades. El análisis basado en métodos digitales nos ha permitido contestar nuestras preguntas de investigación. Existen patrones temáticos y estéticos diferenciados para cada ciudad.

El análisis de contenido indica que existe un uso publicitario de las tres etiquetas generado por los propios usuarios, de lo que podemos inferir que una etiqueta es algo más que un clasificador u organizador de fotografías, y que alienta prácticas de consumo y promoción de productos. Este hallazgo se confirma con el análisis de reacciones, donde la fotografía que mayor cantidad de reacciones recibe tiene fines publicitarios. Esta afirmación es válida para las tres etiquetas estudiadas.

El estudio de analítica textual basado en el recuento de palabras frecuentes evidencia una práctica homogénea en las tres ciudades, aunque cada una de ellas presentan particularidades. Las temáticas asociadas a la fotografía, el viaje, la arquitectura, las experiencias estéticas y el consumo se encuentran presentes en las tres etiquetas.

La analítica visual ha permitido obtener información general sobre la estética de las ciudades y asociar la escala cromática a las temáticas representadas. Así, en \#buenosaires sobresalen las paletas beige y cálidas del centro de la ciudad, en \#cdmx los anaranjados y azules de atardeceres y amaneceres, y en \#madrid los rojos y anaranjados indican la importancia de las personas y la gastronomía.

Retomando a Sassen (1995) podemos observar el carácter especializado de las ciudades en el contexto global. El significado que los usuarios atribuyen a cada ciudad se construye colectivamente de diferentes formas. En \#buenosaires lo son la experiencia de la práctica fotográfica, la ciudad como lugar turístico, y las temáticas vinculadas como la estética: el arte y la moda. En \#cdmx el patrón dominante es el de la estilización del entorno urbano expresado a través de ama- 
neceres, atardeceres, y la apreciación de su arquitectura. En \#madrid en cambio emerge la idea de una ciudad global, conectada con ciudades del mundo.

El análisis de redes visibiliza intereses, temáticas y comunidades acordes a la definición de la fotografía compartida como elemento de exhibición y mensaje comunicativo de intercambio efímero. Los gráficos de red confirman las temáticas recurrentes ya identificadas en la analítica visual así como confirman el carácter socializante de la práctica de la fotografía compartida en Instagram. Al menos una parte de los usuarios de la plataforma concibe su práctica como parte de una comunidad, evidenciada por la aparición recurrentes de etiquetas asociadas a la publicación en Instagram: "instagrammers", "mextagram" y otras similares. Este hallazgo confirma el carácter socializante de la fotografía estudiado por Gómez Cruz (2012) desde el punto de vista etnográfico, y por Brea (2007) desde la teoría de la imagen.

Los usuarios desarrollan estrategias para lograr la visibilidad de sus fotos usando múltiples etiquetas co-ocurrentes y deslocalizando los territorios representados a partir del etiquetado. Podemos suponer entonces que Instagram instaura una suerte de "economía de la visibilidad", donde las reacciones son la moneda con la que se paga la creatividad vernácula.

$\mathrm{El}$ análisis de de reacciones evidencia las diferencias culturales y comunicativas entre el acto de fotografiar y el de mirar una fotografía. En \#cdmx se destaca la alta cantidad de fotografías de amaneceres y atardeceres, pero es la temática urbana y arquitectónica la que recibe mayores reacciones. Los que reciben mayores reacciones por otro lado también hacen un uso económico de las etiquetas, pues su fin es el de la autopromoción.

Hemos identificado un alto nivel de recurrencia temática, estética, y de relaciones entre etiquetas. Éste puede interpretarse en varias direcciones: en relación a las características propias de los objetos representados, debido a la homogeneidad de imaginarios sociales, o también como emergencia de nuevos géneros narrativos asociados a la fotografía compartida cuyos elementos pueden variar según la ciudad que se representa, pero que son estables para cada ciudad. También sugieren la emergencia de codificaciones semióticas propias de Instagram y demuestran la existencia de una gramática de acción (Agre, 1994), donde las acciones aisladas adquieren sentido cuando se las analiza colectivamente. Estos elementos pueden indicar el surgimiento de la fotografía compartida no sólo como práctica cultural sino como género discursivo con sus propias temáticas, estéticas y prácticas. Las recurrencias pueden considerarse codificaciones que se siguen para ser parte de diversas comunidades de práctica materializadas en el uso de etiquetas.

En este trabajo la fotografía urbana compartida emerge como una práctica donde se ponen en práctica estrategias para la visibilidad y la autopromoción en el contexto de una economía global de intercambios simbólicos, línea que deberá ser profundizada tanto teórica como empíricamente.

En cuanto a la representación de las ciudades, se hace visible que éstas son más que una suma de localizaciones. Las tres ciudades estudiadas se representan en Instagram de una forma compleja y novedosa, diferente de los lugares y 
monumentos tradicionales de cada una de ellas, como el Obelisco en Buenos Aires, el Ángel de la Independencia en México o la Puerta de Hierro en Madrid. Se incluyen experiencias estéticas, de turismo, de consumo, de globalización y localización. En la cultura contemporánea confluyen diversas formas de representaciones simbólicas: mundiales, globales y tradicionales (Martín Barbero, 2002). En las primeras, priman estilos y valores culturales desterritorializados y desarraigados de un modo totalizante y enraizado en las prácticas cotidianas de las personas. La globalización pone en circulación una dinámica basada en lo productivo, donde se excluye lo que no lo es. La tradición lucha a través de la comunicación para superar la exclusión y reelaborar su identidad para construir su futuro. Estas tres formas culturales se aprecian en las representaciones estudiadas: se visibilizan conexiones en red entre ciudades del mundo en \#madrid, se representan servicios vinculados al consumo y las industrias culturales tales como la moda, el diseño y el arte en \#buenosaires, y se reinventan las formas de representación entre lo tradicional y la arquitectura moderna en \#cdmx. Es por eso que podemos decir que las fotografías etiquetadas con nombres de ciudades añaden nuevos modos de percibir, narrar y describir las ciudades iberoamericanas.

\section{BIBLIOGRAFIA}

AGRE, P. E. (1994): "Surveillance and Capture: Two Models of Privacy.” The Information Society, 10(2), 101-127.

AoIR. (2012): Ethical Decision-Making and Internet Research: Recommendations from the AoIR Ethics Working Committee, disponible en http://ethics.iit.edu/ecodes/ node/6053 [consulta 12-04-2018]

BERRY, D. (2011): "The Computational Turn: Thinking About the Digital Humanities." Culture Machine, 12, disponible en http://www.culturemachine.net/index.php/cm/ article/viewarticle/440 [consulta: 26-11-2016]

BIG DATA I "Definition of Big Data" in English by Oxford Dictionaries. (s/f): Oxford Dictionaries I English, disponible en https://en.oxforddictionaries.com/definition/ big_data [consulta: 17-09-2017]

BORRA, E., Y RIEDER, B. (2014): "Programmed Method: Developing a Toolset for Capturing and Analyzing Tweets." Aslib Journal of Information Management, 66(3), 262-278.

BREA, J. L. (2007): Cultura_Ram: mutaciones de la cultura en la era de su distribución electrónica, Barcelona, Gedisa.

British Psychological Society. (2010): Code of Human Research Ethics. Leicester: Author http://www.bps.org.uk/sites/default/files/documents/code of human research ethics.pdf [consulta: 17-09-2017]

BRITISH PSYCHOLOGICAL SOCIETY (2013): Ethics Guidelines for Internet-Mediated Research. Leicester: Autor, disponible en http://www.bps.org.uk/system/files/ Public\%20files/inf206-guidelines-for-internet-mediated-research.pdf [consulta: 2611-2016] 
BURGESS, J., BRUNS, A. (2015): "Easy Data, Hard Data: The Politics and Pragmatics of Twitter Research After the Computational Turn", en Compromised Data: From Social Media to Big Data, New York, Bloomsbury Academic.

COLOMBO, G., CIUCCARELLI, P., MAURI, M. (2017): "Visual Geolocations. Repurposing Online Data to Design Alternative Views." Big Data and Society 1( 4)

CRESWELL, J. W. (2014): Research design: qualitative, quantitative, and mixed methods approaches, Thousand Oaks, California, SAGE Publications.

DE CERTEAU, M. (1996): La Invención de lo cotidiano, México, Universidad Iberoamericana.

FONTCUBERTA, J. (1997): El beso de Judas: fotografía y verdad, Barcelona, G. Gili.

FONTCUBERTA, J. (2011, noviembre 5): "Por un manifiesto postfotográfico.", disponible en http://www.lavanguardia.com/cultura/20110511/54152218372/por-un-manifiesto-posfotografico.html [consulta: 08-02-2017]

FÖRSTER, T., LAMERZ, L., MAINKA A., PETERS, I. (2014): "The Tweet and the City: Comparing Twitter Activities in Informational World Cities". Presentado en DGI Konferenz, Frankfurt, disponible en https://www.academia.edu/15646568/ The Tweet and the City Comparing Twitter Activities in Informational World Cities [consulta: 26-11-2016]

FULTON, K. (2014): Screen Scraping: how to stop the Internet's Invisible Data Leeches, disponible en http://www.techradar.com/news/internet/web/screen-scraping-howto-stop-the-internet-s-invisible-data-leaches-1214404 [consulta: 15-05-2017]

GANDOLMI, A., Y HAIDER, M. (2015): "Beyond the Hype: Big Data Concepts, Methods, and Analytics.” International Journal of Information Management, 35(2), 137-144.

GOLDBECK, J. (2013): Analyzing the Social Web,Waltham Massachusetts, Elsevier.

GÓMEZ CRUZ, E. (2012): De la cultura Kodak a la imagen en red : una etnografía sobre fotografía digital, Barcelona, UOC.

HALL, S. (2013): “The work of representation", en Representation. London, Sage y Open University

HEWSON, C. (2016): "Ethics Issues in Digital Methods Research", en Digital Methods for Social Science (pp. 206-221), Palgrave Macmillan, London

HOCHMAN, N., Y MANOVICH, L. (2013): “Zooming into an Instagram City: Reading the Local through Social Media.” First Monday, 18(7), disponible en http://firstmonday.org/ojs/index.php/fm/article/view/4711[consulta: 26-11-2016]

INSTAGRAM (2013) Configuración de la privacidad e información, disponible en https://help.instagram.com/196883487377501/?helpref=hc fnav [consulta: 26-112016]

JENKINS, H. (2009): Fans, blogueros y videojuegos: la cultura de la colaboración, Barcelona, Paidós.

JENSEN, J. (2017): Instagram Marketing with Instagram Bot, disponible en https://medium.com/@ JordonJensen/instagram-marketing-with-instagram-bot-8ab6a40dc5a0 [consulta: 13-04-2017]

HIGHFIELD, T., Y LEAVER, T. (2014): “A Methodology for Mapping Instagram Hashtags." First Monday, 20(1), disponible en http://firstmonday.org/ojs/index.php/fm/ article/view/5563 [consulta: 28-08-2017]

HIGHFIELD, T Y LEAVER, T. (2016): "Instagrammatics and Digital Methods: Studying visual social media, from selfies and GIFs to memes and emoji." Communication Research and Practice. 2. 47-62. 
HINE, C. (2005): Virtual Methods: Issues in Social Research on The Internet, Oxford,New York, Berg.

HINE, C. (2015): Ethnography for the Internet: Embedded, Embodied and Everyday, London, Bloomsbury Academic.

MANOVICH, L. (2009): "Cultural Analytics: Visualizing Patterns in the Era of more Media.", disponible en http://www.manovich.net [consulta: 14-05-2017]

MANOVICH, L. (2011a): "Trending: The Promises and the Challenges of Big Social Data". Recuperado el 29/08/17 a partir de http://manovich.net/content/04projects/067-trending-the-promises-and-the-challenges-of-big-social-data/64-article-2011.pdf [consulta: 29-08-2017]

MANOVICH, L. (2011b): "What is a Visualization?" Visual Studies, 26(1), 36-49.

MANOVICH, L. (2012): "How to Compare One Million Images?", en Understanding Digital Humanities (pp. 249-278): Palgrave Macmillan, London. 4

MANOVICH, L, STEFANER M., YAZDANI, M. ET AL (2014) "Selfie City. Investigating the Style of self-portraits (selfies) in five Cities across the World", disponible en http://www.selfiecity.net/ [consulta: 29-08-2017]

MANOVICH, L. (2016): "Instagram and the Contemporary Image", disponible en http:// www.manovich.net [consulta 14-05-17]

MARRES, N., Y WELTEVREDE, E. (2013): "Scraping the Social? Issues in Live Social Research.” Journal of Cultural Economy, 6(3), 313-335.

MARRES, N. (2017): Digital Sociology: The Reinvention of Social Research, John Wiley \& Sons.

MARTÍN-BARBERO, J. (2001): De los medios a las mediaciones: comunicación, cultura y hegemonía, México: G. Gili.

MARTÍN-BARBERO, J. (2002): La globalización en clave cultural: una mirada latinoamericana, Conferencia para el coloquio internacional Globalismo y Pluralismo. Montreal: 22 al 27 de abril de 2002, disponible en www.er.uqam.ca/nobel/gricis/ actes/bogues/Barbero.pdf [consulta:12-04-18]

MENESES ROCHA, M. E. M. (2018): “Grandes datos, grandes desafíos para las ciencias sociales" Revista Mexicana de Sociología, 80(2)

MICHEL, A., Y HOLPUCH, A. (2012): Why did Facebook buy Instagram for a whopping $\$ 1$ bn?, disponible en https://www.theguardian.com/commentisfree/cifamerica/2012/apr/09/facebook-instagram-1bn-storify [consulta: 29-08-2017]

MORENO, A., REDONDO, T. (2016): "Text Analytics: the Convergence of Big Data and Artificial Intelligence." International Journal of Interactive Multimedia and Artificial Intelligence, 3 (57-64)

MORETTI, F. (2007): La literatura vista desde lejos. Barcelona: Marbot.

MORETTI, F. (2015): Distant reading. London: Verso.

NIEDERER, S., Y TAUDIN CHABOT, R. (2015): "Deconstructing the Cloud: Responses to Big Data Phenomena from Social Sciences, Humanities and the Arts." Big Data and Society, 2(2)

NORUZI, A. (2006) "Folksonomies: (Un)Controlled Vocabulary?.” Knowledge Organization. 33.

OH, C., LEE, T., KIM, Y., PARK, S., \& SUH, B. (2016): “Understanding Participatory Hashtag Practices on Instagram: A Case Study of Weekend Hashtag Project.” CHI'16 Extended Abstracts, May 07-12, 2016, San Jose, CA, USA, disponible en https:// www.researchgate.net/publication/302074044 Understanding Participatory Hashtag Practices on Instagram A Case Study of Weekend Hashtag Project [consultado: 12/04/2018] 
ORTEGA GUTIERREZ, E, \& CALOCA LAFONT, E. (2017): Los métodos digitales: miradas cercanas y distantes. Una discusión relevante. Virtualis 3(18), 8-12.

PRESNER, T., SHEPARD, D. Y KAWANO, Y. (2010): HyperCities. Cambridge, Mass: Harvard University Press.

PRESS, G. (2014): 12 Big Data Definitions: What's Yours?, disponible en http://www. forbes.com/sites/gilpress/2014/09/03/12-big-data-definitions-whats-yours/ [consultado: 13-05-2017]

ROGERS, R. (2009): “The End of Virtual. Digital Methods.”, disponible en http://www. govcom.org/rogers oratie.pdf [consultado: 13-05-2017]

ROGERS, R. (2013): Digital Methods, Cambridge, Massachusetts: The MIT Press.

ROGERS, R. (2015): "Digital Methods for Web Research", en Emerging Trends in the Social and Behavioral Sciences. Hoboken, NJ: John Wiley and Sons, Inc.

ROGERS, R. (2016): “Otherwise Engaged: Critical Analytics and the Meanings of Engagement.", disponible en https://www.youtube.com/watch?v=sNwl-qGrK7M [consultado: 17-09-2017]

ROSE, G. (2016): Visual Methodologies: an Introduction to Researching with Visual Materials, London, Sage

SASSEN, S. (1995): "La ciudad global: una introducción al concepto y sus historia". Brown Journal of World Affairs 11 (2), 27-43

SAVAGE,M., y BURROWS, R. (2007): "The Coming Crisis of Empirical Sociology". Sociology, 41(5), 885-899.

STATISTA (2016) Countries with most Instagram Users 2016, disponible en https:// www.statista.com/statistics/578364/countries-with-most-instagram-users/ [consultado: 17-09-2017]

STATISTA (2017a) Instagram monthly Active Users 2017, disponible en https://www. statista.com/statistics/253577/number-of-monthly-active-instagram-users/ [consultado: 17-09-2017]

STATISTA (2017b) Instagram: Global Mobile Internet Advertising Revenue 2017, disponible en https://www.statista.com/statistics/448157/instagram-worldwide-mobile-internet-advertising-revenue/ [consultado: 17-09-2017]

STREATFIELD, B. (2015) Rise of a Tech Giant: the History of Instagram, disponible en Daily http://www.telegraph.co.uk/technology/technology-video/12064686/Rise-ofa-tech-giant-the-history-of-Instagram.html [consultado: 17-09-2017]

SCOLARI, C. (2008): Hipermediaciones: elementos para una teoría de la comunicación digital interactiva. Barcelona, Gedisa.

THOMAS K., COOK, K., eds. (2005) Illuminating the Path: Research and Development Agenda for Visual Analytics. IEEE-Press, disponible en http://vis.pnnl.gov/pdf/RD Agenda VisualAnalytics.pdf [consultado: 17-09-2017]

TUFEKCI, Z. (2014): "Big Questions for Social Media Big Data: Representativeness, Validity and Other Methodological Pitfalls". ICWSM, 14, 505-514.

TURNER, P. (2014): “The Figure and Ground of Engagement”. AI and Society, 29(1), $33-43$.

VAN DIJCK, J. (2011): "Flickr and the Culture of Connectivity: Sharing views, experiences, memories". Memory Studies, 4(4), 401-415.

VAN DIJCK, J. (2016): La cultura de la conectividad: una historia crítica de las redes sociales. Buenos Aires, Siglo Veintiuno. 
VENTURINI, T., JACOMY, M., Y CARVALHO P. D. (2015): "Visual Network Analysis”, disponible en http://www.tommasoventurini.it/wp/wp-content/uploads/2014/08/ Venturini-Jacomy Visual-Network-Analysis WorkingPaper.pdf [consultado: 0709-2017]

VERÓN, E. (1987) La semiosis social. Fragmentos de una teoría de la discursividad, Buenos Aires, Gedisa.

VERÓN, E. (2013) La semiosis social, 2. Ideas, momentos, interpretantes, Buenos Aires, Paidós. 
